\title{
Nonlinear Time-Delay Suspension Adaptive Neural Network Active Control
}

\author{
Yue Zhu and Sihong Zhu \\ College of Engineering, Nanjing Agricultural University, Nanjing 210031, China \\ Correspondence should be addressed to Yue Zhu; zhuyue_jin@163.com
}

Received 2 July 2014; Accepted 15 August 2014; Published 27 August 2014

Academic Editor: Zheng-Guang Wu

Copyright ( 2014 Y. Zhu and S. Zhu. This is an open access article distributed under the Creative Commons Attribution License, which permits unrestricted use, distribution, and reproduction in any medium, provided the original work is properly cited.

Considering the time-delay in control input channel and the nonlinear spring stiffness characteristics of suspension, a quartervehicle magneto rheological active suspension nonlinear model with time-delay is established in this paper. Based on the time-delay nonlinear model, an adaptive neural network structure for magneto rheological active suspension is presented. By recognizing and training the adaptive neural network, the adaptive neural network active suspension controller is obtained. Simulation results show that the presented method can guarantee that the quarter-vehicle magneto rheological active suspension system has satisfying performance on the Elevel very poor ground.

\section{Introduction}

For engineering vehicles, farm tractors, military vehicles, and so on, the road conditions are usually very poor. Therefore, vibration problem is prominent particularly [1]. Seat suspension has been widely used as a simple and effective method to improve ride quality of vehicle which is directly related to driver fatigue, discomfort, and safety [2]. In recent years, the active suspension control research has received the widespread attention of scholars at home and abroad, in the aspect of theoretical analysis and physical test [3-8].

Vehicle suspension system is a complex dynamic system; the road input is a random process and has a strong uncertainty, while the system itself has strong nonlinearity characteristic; therefore, it is difficult to obtain ideal control effect by using conventional control methods $[5,6]$.

The neural network is a kind of powerful tool to deal with uncertainty and nonlinearity; it can parallel computing and distribute information storage, while it has strong fault tolerance and self-learning ability. Hence, neural network is suitable for the complex system modeling and control [9-11].

In this paper, in order to reduce the vibration of magneto rheological active suspension system, adaptive neural network active suspension controller is designed. At first, a quarter-vehicle active suspension nonlinear model with timedelay is established by considering the time-delay in control input channel of magneto rheological active suspension system and the nonlinear spring stiffness characteristics of suspension. Then, an adaptive neural network structure for magneto rheological active suspension is presented according to the time-delay nonlinear model. Next, the adaptive neural network active suspension controller is obtained by recognizing and training the adaptive neural network. At last, Elevel ground which is very poor road condition is considered for a quarter-vehicle magneto rheological active suspension system. Simulation shows that the presented method can guarantee that the system has satisfying performance.

The remainder of this paper is organized as follows. In Section 2, the considered quarter-vehicle magneto rheological active suspension time-delay nonlinear model is presented. Adaptive neural network structure, neural network identification, and neural network training are given in Section 3 and the adaptive neural network active suspension controller is obtained in Section 3 as well. Simulation on a quarter-vehicle magneto rheological active suspension system under E_level very poor ground is illustrated in Section 4. Section 5 draws the conclusions of this paper. 


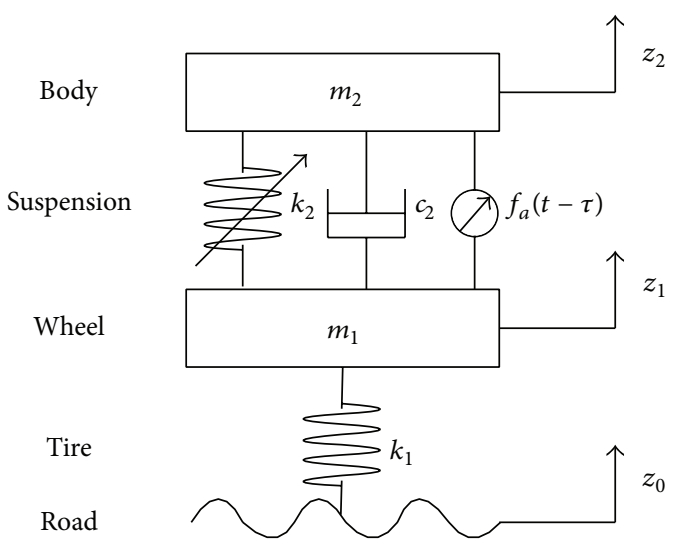

FIGURE 1: Quarter-vehicle model with a magneto rheological active suspension.

\section{Quarter-Vehicle Magneto Rheological Active Suspension Time-Delay Nonlinear Model}

In this paper, quarter-vehicle model for active control of magneto rheological seat suspension system is studied. At the same time, the nonlinear stiffness characteristics of the suspension spring and control time-delay characteristics are considered. Figure 1 shows a quarter-vehicle model of an active suspension system.

Among them, $m_{2}$ is body quality, $m_{1}$ is wheel quality, $k_{2}$ is suspension stiffness, $c_{2}$ is damping coefficient, $k_{1}$ is tire equivalent stiffness coefficient, $z_{2}$ is the displacement of body, $z_{1}$ is displacement of wheels, $z_{0}$ is the ground displacement excitation, and $f_{a}(t-\tau)$ is active control. Here, the variable stiffness spring of restoring force-displacement relationship is expressed as [12] $f_{s}=k_{2} \Delta z+\varepsilon k_{2} \Delta z^{3}, \Delta z=z_{2}-z_{1}$, $\varepsilon$ is nonlinear spring ratio. When $k_{2}=27358, \varepsilon=10$ restoring force $f_{s}$ and displacement $\Delta z$ relationship is shown in Figure 2. is

Dynamic differential equation for the suspension system

$$
\begin{aligned}
& m_{2} \ddot{z}_{2}+c_{2}\left(\dot{z}_{2}-\dot{z}_{1}\right)+k_{2}\left(z_{2}-z_{1}\right)+\varepsilon k_{2}\left(z_{2}-z_{1}\right)^{3} \\
& =f_{a}(t-\tau) \\
& m_{1} \ddot{z}_{1}+c_{2}\left(\dot{z}_{1}-\dot{z}_{2}\right)+k_{1}\left(z_{1}-z_{0}\right)-k_{2}\left(z_{2}-z_{1}\right) \\
& \quad-\varepsilon k_{2}\left(z_{2}-z_{1}\right)^{3}=-f_{a}(t-\tau)
\end{aligned}
$$

as $x=\left[x_{1}, x_{2}, x_{3}, x_{4}\right]^{T}=\left[z_{2}, z_{1}, \dot{z}_{2}, \dot{z}_{1}\right]^{T}=\left[q^{T}, p^{T}\right]^{T}$.

$u=f_{a}$; assume acceleration $\ddot{z}_{2}$, velocity $\dot{z}_{2}, \dot{z}_{1}$, and displacement $z_{2}, z_{1}$ are measurable; the introduction of auxiliary control variable is written as

$$
\bar{u}(t-\tau)=u(t-\tau)-\varepsilon k_{2}\left(z_{2}-z_{1}\right)^{3}
$$

and (1) can be rewritten into

$$
\dot{x}=A x+B \bar{u}(t-\tau)+B_{w} z_{0},
$$

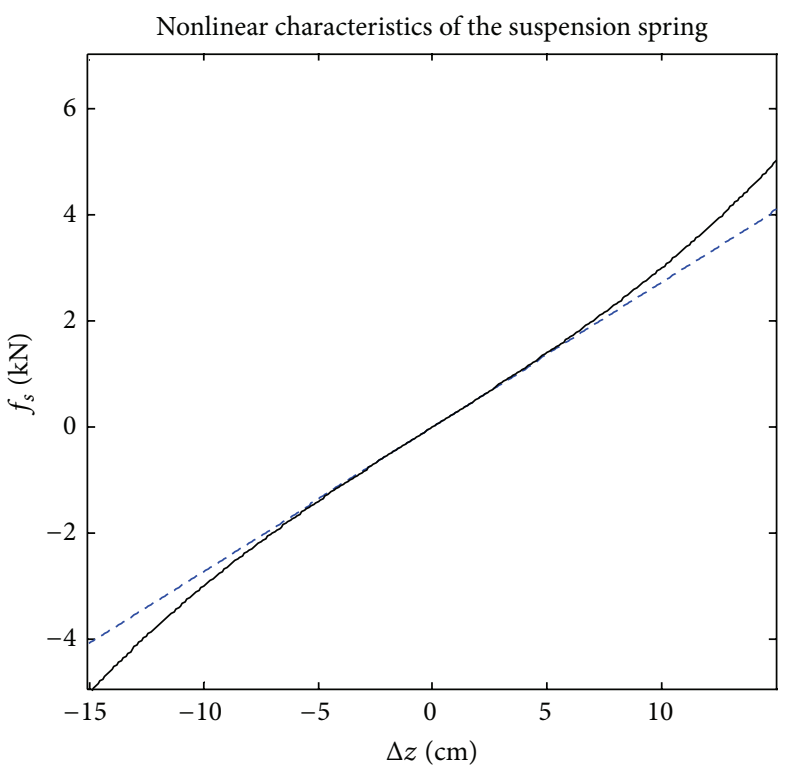

FIGURE 2: Force-displacement curve of nonlinear spring.

$$
\begin{gathered}
A=\left[\begin{array}{cccc}
0 & 0 & 1 & 0 \\
0 & 0 & 0 & 1 \\
\frac{-k_{2}}{m_{2}} & \frac{k_{2}}{m_{2}} & \frac{-c_{2}}{m_{2}} & \frac{c_{2}}{m_{2}} \\
\frac{k_{2}}{m_{1}} & \frac{-k_{2}-k_{1}}{m_{1}} & \frac{c_{2}}{m_{1}} & \frac{-c_{2}}{m_{1}}
\end{array}\right], \\
B=\left[\begin{array}{llll}
0 & 0 & \frac{1}{m_{2}} & \frac{-1}{m_{1}}
\end{array}\right]^{T}, \quad B_{w}=\left[\begin{array}{llll}
0 & 0 & 0 & \frac{k_{1}}{m_{1}}
\end{array}\right] .
\end{gathered}
$$

The corresponding nominal system model of (3) is

$$
\dot{x}=\left[\begin{array}{ll}
A_{11} & A_{12} \\
A_{21} & A_{22}
\end{array}\right]\left[\begin{array}{l}
q \\
p
\end{array}\right]+\left[\begin{array}{l}
B_{1} \\
B_{2}
\end{array}\right] \bar{u}(t-\tau)
$$

where

$$
\begin{gathered}
A_{11}=\left[\begin{array}{ll}
0 & 0 \\
0 & 0
\end{array}\right], \quad A_{12}=\left[\begin{array}{ll}
1 & 0 \\
0 & 1
\end{array}\right], \quad B_{1}=\left[\begin{array}{l}
0 \\
0
\end{array}\right], \\
A_{21}=\left[\begin{array}{cc}
\frac{-k_{2}}{m_{2}} & \frac{k_{2}}{m_{2}} \\
\frac{k_{2}}{m_{1}} & \frac{-k_{2}-k_{1}}{m_{1}}
\end{array}\right], \quad B_{2}=\left[\begin{array}{c}
\frac{1}{m_{2}} \\
\frac{-1}{m_{1}}
\end{array}\right], \\
A_{22}=\left[\begin{array}{cc}
\frac{-c_{2}}{m_{2}} & \frac{c_{2}}{m_{2}} \\
\frac{c_{2}}{m_{1}} & \frac{-c_{2}}{m_{1}}
\end{array}\right] .
\end{gathered}
$$

\section{The Design of Adaptive Neural Network Active Suspension Controller}

3.1. Adaptive Neural Network Structure. Adaptive neural network system structure is shown in Figure 3. The system consists of three parts: the controlled active suspension, the neural network identifier AN1, and the neural network 


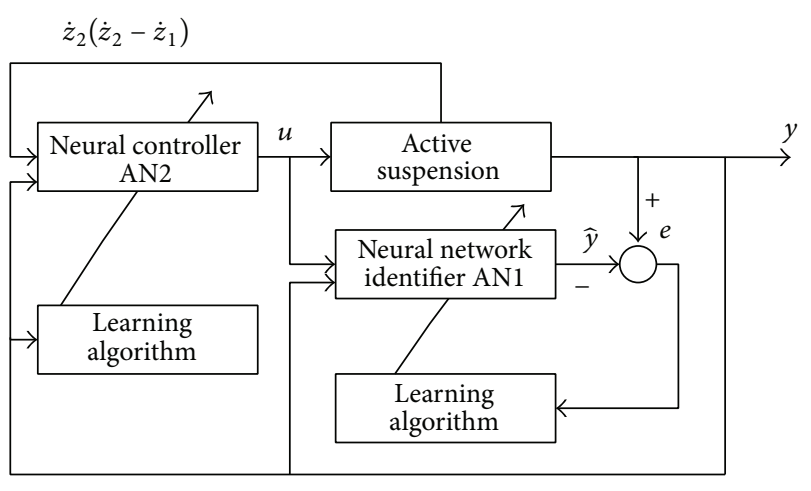

FIGURE 3: Adaptive neural network structure.

controller AN2. AN1 is used for online identification of active suspension systems; AN2 is used to realize the network parameters adjustment by tuning the network weights and the threshold online and then to get the best effect of vibration reduction.

In Figure 3, output $y$ is the body acceleration, control signal $u$ is damping force, and its normalized range is $0 \sim 1$. The common way to implement $u$ is to regulate electrohydraulic proportional throttle valve flow area or valve core displacement. $\dot{z}_{2}\left(\dot{z}_{2}-\dot{z}_{1}\right)$ is as an input for the neural network controller AN2. The input for neural network identifier AN1 is the body acceleration and control signal $u$.

3.2. Neural Network Identification. The road excitation can be viewed as a white noise signal and it is suitable to identify active suspension system by using nonlinear autoregressive moving average (NARMA) model; namely,

$$
\begin{gathered}
y(k)=f[y(k-1), \ldots, y(k-n), \bar{u}(k-1-\tau), \ldots, \\
\bar{u}(k-m-\tau), v(k-1), \ldots, v(k-l)],
\end{gathered}
$$

where $y(k)$ is for body acceleration at the $k$ th step; $\bar{u}(k-1-\tau)$ is for the control signal at the $(k-1-\tau)$ th step; $v(k-1)$ is for road random input (white noise) at the $(k-1)$ th step.

AN1 identifies the system model and multilayer feedforward neural network was used by the network structure. Network is composed of two layers: the first layer is input layer and has $n+m$ inputs. Hyperbolic function is chosen as neurons transformation; each of the neurons has a threshold. The second layer is output layer and is with one neuron which represents the estimate of the system output. Proportion function is selected as neuron function and it also has neuron threshold.

3.3. The Adaptive Neural Network Controller. The structure of the neural network controller AN2 is shown in Figure 4. The network has two inputs and one output. The first input $z_{1}^{(0)}=\psi_{z_{2}}$ is the root mean square value of the body acceleration; the second input $z_{2}^{(0)}=\dot{z}_{2}\left(\dot{z}_{2}-\dot{z}_{1}\right)$ is the product of the speed of the suspension. Network output value $\mu=r / r_{\max }$ is the variable damping. In order to facilitate network training, suppose $r_{\max }=1 \times 10^{5}\left(\mathrm{~N} \cdot \mathrm{s}^{2} / \mathrm{m}^{2}\right)$. Network

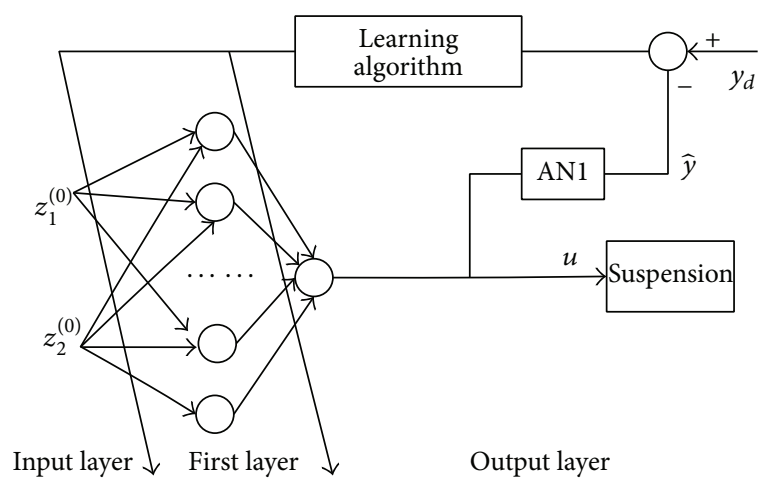

FIGURE 4: Adaptive neural network controller.

structure applies multilayer feed-forward neural network. The network has two layers (not including the input layer); the first layer is composed of 10 neurons with thresholds; the hyperbolic function is used as neurons transformation function $S$. The second layer has a neuron with threshold; the sigmoid function is utilized as neurons transformation function $S$, so that the output of the network can be always in the range of $0 \sim 1$.

In order to obtain good performance, Marquardt backpropagation algorithm (MBP algorithm) which is of high training efficiency is used in training neural network identifier ANl. During training, the error between desired body acceleration and the output of neural network identifier ANl is as the input for MBP algorithm. And the weights and thresholds of AN1 keep unchanging.

Because the desired control signal is unknown at the very beginning, neural network controller AN2 is cascaded with neural network identifier AN1, as shown in Figure 3. During training, MBP algorithm is employed as well, but the weights and thresholds of AN2 are changed, in order to obtain and optimize adaptive neural network controller.

The input-output relationship of the first layer is

$$
\begin{gathered}
S_{i}^{(1)}=\sum_{j=0}^{2} \omega_{i j}^{(1)} x_{j}^{(0)}\left(x_{0}^{(0)}=1, \omega_{r 0}^{(1)}=\theta_{r}^{(1)}\right) \\
x_{i}^{(1)}=f\left(S_{i}^{(1)}\right)=\frac{1-e^{-2 S_{i}^{(1)}}}{1+e^{-2 S_{i}^{(1)}}}, \quad i=1,2, \ldots, 10, j=0,1,2 .
\end{gathered}
$$

The input-output relationship of the first layer is

$$
\begin{gathered}
S_{i}^{(2)}=\sum_{j=0}^{10} \omega_{i j}^{(2)} x_{j}^{(1)}\left(x_{0}^{(0)}=1, \omega_{r 0}^{(2)}=\theta_{r}^{(2)}\right), \\
u=f\left(s_{i}^{(2)}\right)=\frac{1}{1+e^{-2 s_{j}^{(2)}}} \quad(j=0,1,2, \ldots, 10) .
\end{gathered}
$$




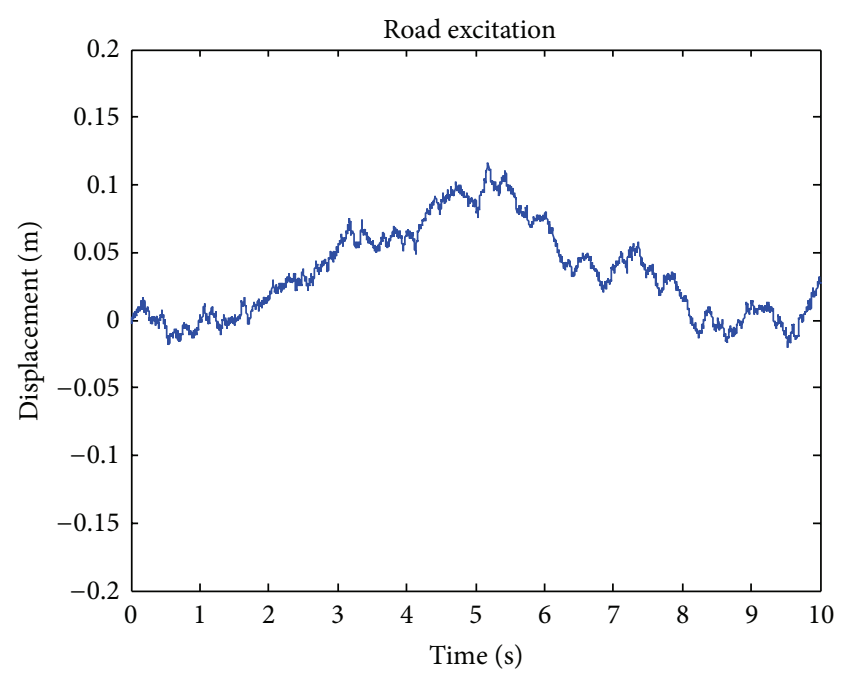

Figure 5: Road excitation.

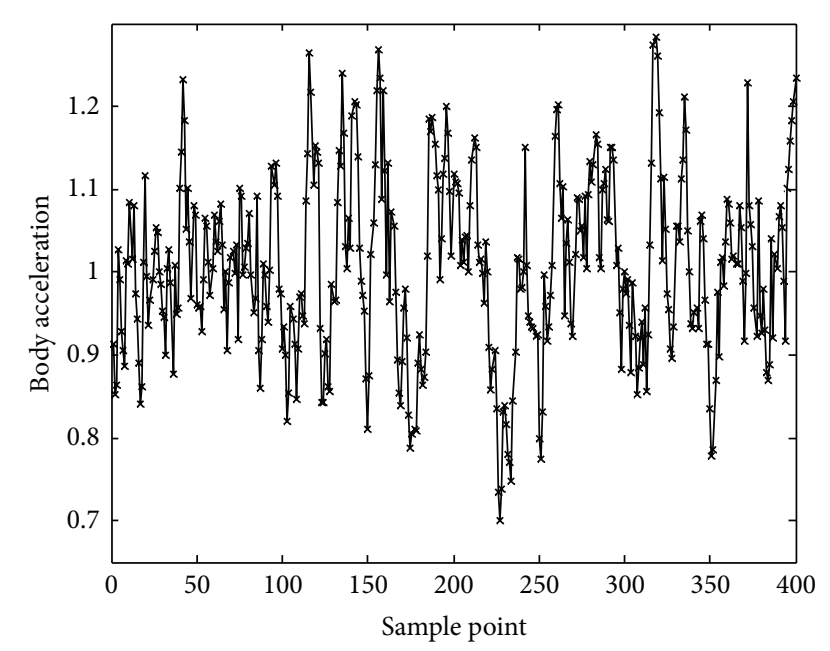

FIGURE 6: Training result.

To improve the training algorithm, the weights and thresholds are adjusted according to the following laws:

$$
\begin{gathered}
\omega_{i j}^{(q)}(k+1)=\omega_{i j}^{(q)}(k)+\alpha\left[(1-\eta) D_{i j}^{q}(k)+\eta D_{i j}^{q}(k-1)\right], \\
D_{i j}^{q}=-\sum_{p=1}^{p} \frac{\partial E_{p}}{\partial \omega_{i j}}, \quad E_{p}=\frac{1}{2}\left(y_{d p}-\widehat{y}_{p}\right)^{2} ; \quad q=1,2 .
\end{gathered}
$$

\section{Case Study}

Consider the active suspension system [13]: $m_{1}=70 \mathrm{~kg}$, $k_{1}=309.511 \mathrm{~kg}, m_{2}=310 \mathrm{~kg}, k_{2}=27.358 \mathrm{KN} / \mathrm{m}$, and $c_{2}=0.984 \mathrm{KN} \mathrm{s} / \mathrm{m}$.

For E_level ground, the road roughness power spectrum density is $G_{q}\left(n_{0}\right)=1024 \times 10^{-6}, n_{0}=0.1$. Suppose forward velocity $v_{0}=7 \mathrm{~km} / \mathrm{h}$. The ground excitation displacement is shown in Figure 5.

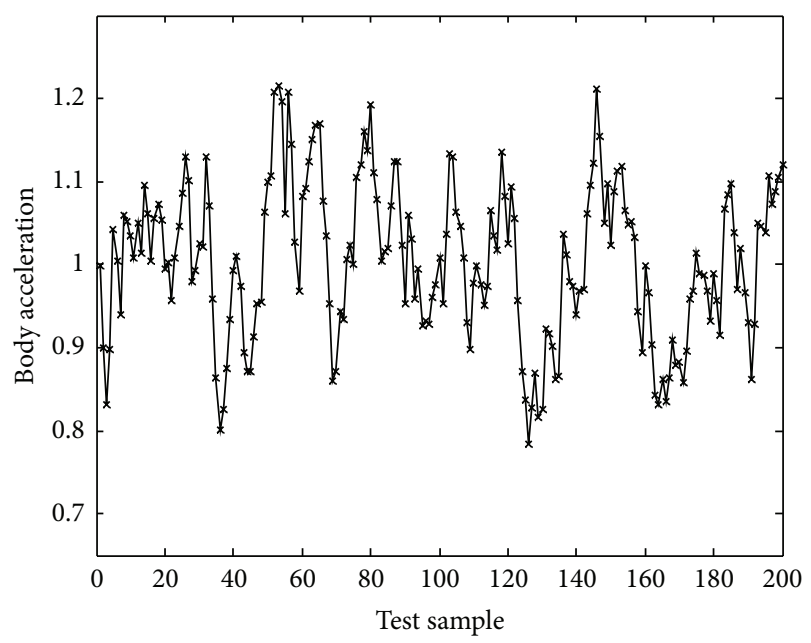

FIgURE 7: Test result.

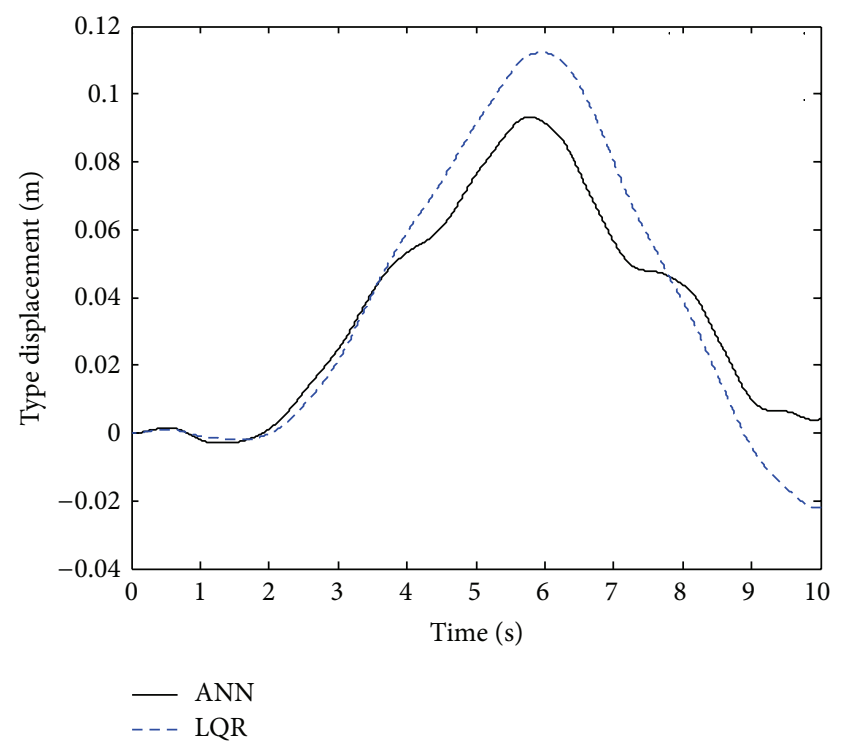

Figure 8: Tire displacement.

Figure 6 shows the training results, which illustrates the comparison between the test data of actual output and the network training output data. One can see that the network training output is consistent with the system test output very well. Figure 7 shows the test results; one can see that the network test output is consistent with the system test output very well.

In order to make comparison, $\mathrm{LQR}$ controller is designed as well in this paper, and $Q_{\mathrm{LQR}}=\operatorname{diag}\{1,1,1,1\} ; R_{\mathrm{LQR}}=$ 0.000001 is chosen for simulation. The simulation results are shown in Figures 8, 9, and 10, where the solid black lines represent the control results under the presented adaptive neural network (ANN) controller, while the dash blue lines represent the control results under LQR controller.

Figures 8 10 show that, on the terrible E_level ground, compared with the LQR controller, the presented adaptive neural network controller in this paper can significantly 


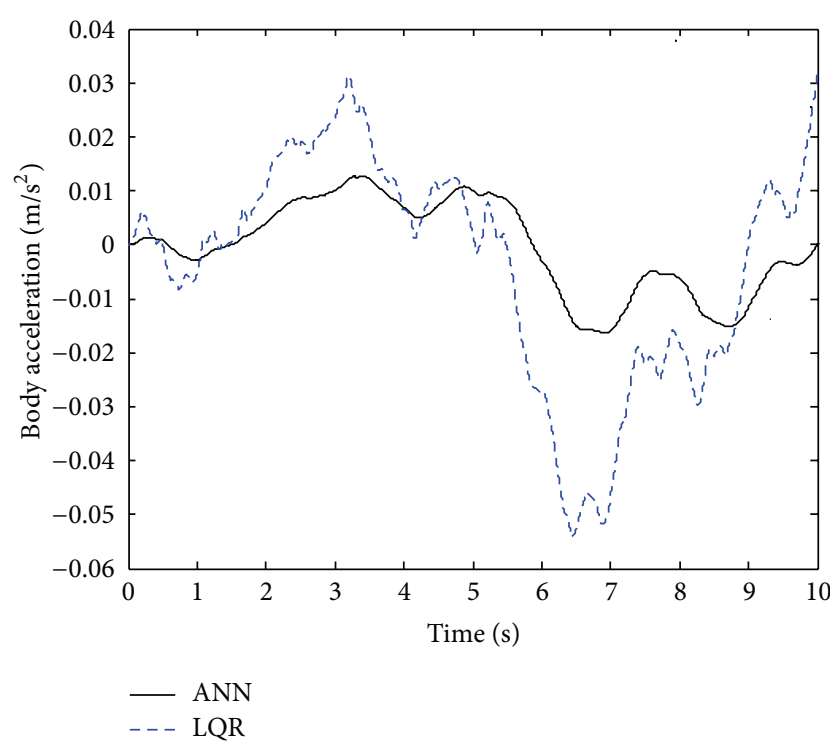

Figure 9: Body acceleration.

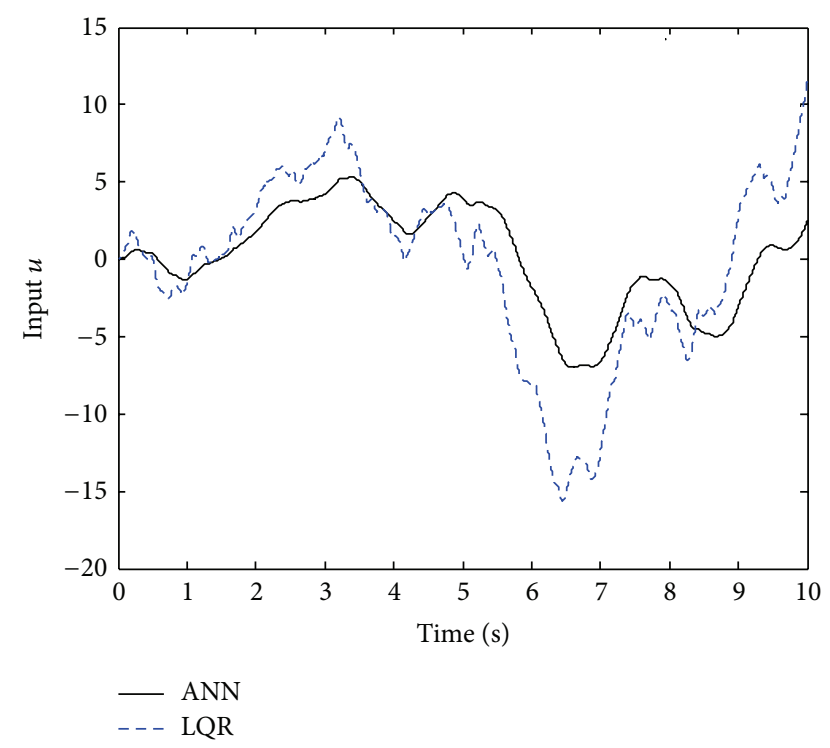

FIGURE 10: Input force.

reduce the peak values of tire displacement, body acceleration, and control signal, and the body acceleration and control signal are smoother. Therefore, the proposed adaptive neural network controller for magneto rheological active suspension system is effective.

\section{Conclusions}

In this paper, an adaptive neural network control strategy is presented for a magneto rheological active suspension system with time-delay in control input channel and the nonlinear spring stiffness characteristics. On the basis of the time-delay nonlinear model and adaptive neural network structure, and by recognizing and training the adaptive neural network, the adaptive neural network active suspension controller is obtained. Simulation on a quarter-vehicle magneto rheological active suspension system under Ellevel ground shows that the proposed method can significantly reduce the peak values of tire displacement, body acceleration, and control signal, and the body acceleration and control signal are smoother.

\section{Conflict of Interests}

The authors declare that there is no conflict of interests regarding the publication of this paper.

\section{Acknowledgments}

This work was supported by Natural Science Foundation of China (51275249) and Talent Introduction Foundation of Engineering College Nanjing Agricultural University (Rcqd11-06).

\section{References}

[1] F. Yu and Y. Zhang, "Technology of regenerative vehicle active suspensions," Transactions of the Chinese Society of Agricultural Machinery, vol. 41, no. 1, pp. 1-5, 2010.

[2] F. Feng, Y. Liu, L.-X. Li, and B.-C. Wen, "Optimal control for nonlinear vehicle suspension frames," Chinese Journal of Construction Machinery, vol. 8, no. 2, pp. 143-146, 2010.

[3] W. Ruochen, C. Long, Z. Xiaoliang, and Z. Xinghua, "Design and test of semi-active air suspension system of vehicle," Transactions of the Chinese Society for Agricultural Machinery, vol. 43, no. 4, pp. 6-9, 2012.

[4] Y. Li and L. Zheng, "Nonlinear control methods of automotive semi-active suspension based on the MR damper," Chinese Journal of Mechanical Engineering, vol. 41, no. 5, pp. 31-37, 2005.

[5] H. Gao, Y. Zhao, and W. Sun, "Input-delayed control of uncertain seat suspension systems with human-body model," IEEE Transactions on Control Systems Technology, vol. 18, no. 3, pp. 591-601, 2010.

[6] W. Sun, Y. Zhao, J. Li, L. Zhang, and H. Gao, "Active suspension control with frequency band constraints and actuator input delay," IEEE Transactions on Industrial Electronics, vol. 59, no. 1, pp. 530-537, 2012.

[7] L. Wei and J. Griffin, "The prediction of seat transmissibility from measures of seat impedance," Journal of Sound and Vibration, vol. 214, no. 1, pp. 121-137, 1998.

[8] A. K. Samantaray, "Modeling and analysis of preloaded liquid spring/damper shock absorbers," Simulation Modelling Practice and Theory, vol. 17, no. 1, pp. 309-325, 2009.

[9] B. F. Spencer, S. J. Dyke, M. K. Sain, and J. D. Carlson, "Phenomenological model of magnetorheological damper," Journal of Engineering Mechanics, vol. 123, no. 3, pp. 230-238, 1997.

[10] A. Ghazi Zadeh, A. Fahim, and M. El-Gindy, "Neural network and fuzzy logic applications to vehicle systems: literature survey," International Journal of Vehicle Design, vol. 18, no. 2, pp. 132-193, 1997.

[11] D. Cebon, F. H. Besinger, and D. J. Cole, "Control strategies for semi-active lorry suspension," Proceeding of Machine Engineering, vol. 21, pp. 161-178, 1996. 
[12] H. Zhao, H. Huang, H. Li, and J. Zhang, "Dynamic characteristics of vehicle suspension, with non-linear springs," Journal of System Simulation, vol. 13, no. 5, pp. 649-651, 2001.

[13] K.-G. Sung, Y.-M. Han, J.-W. Cho, and S.-B. Choi, "Vibration control of vehicle ER suspension system using fuzzy moving sliding mode controller," Journal of Sound and Vibration, vol. 311, no. 3-5, pp. 1004-1019, 2008. 


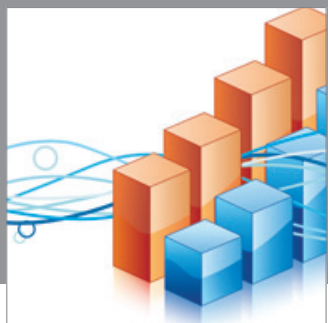

Advances in

Operations Research

mansans

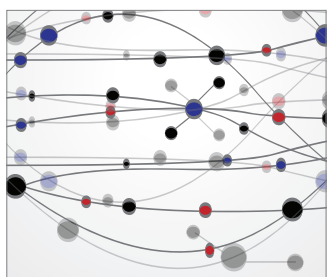

The Scientific World Journal
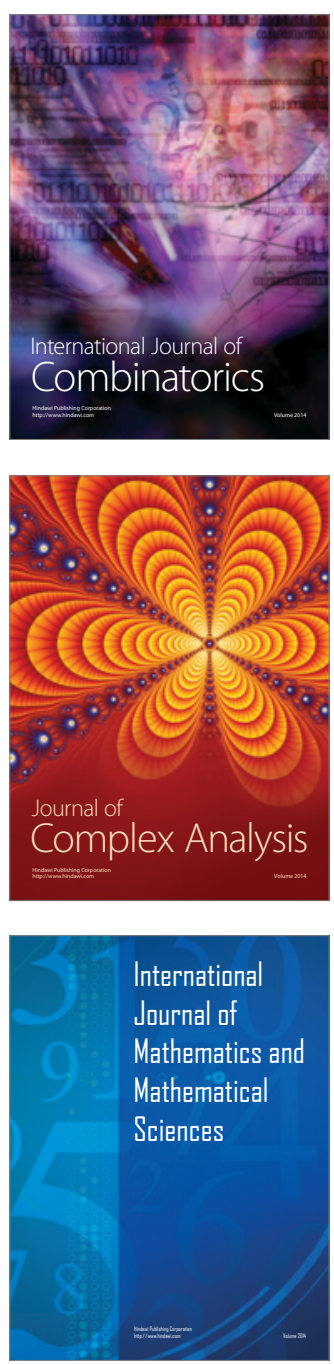
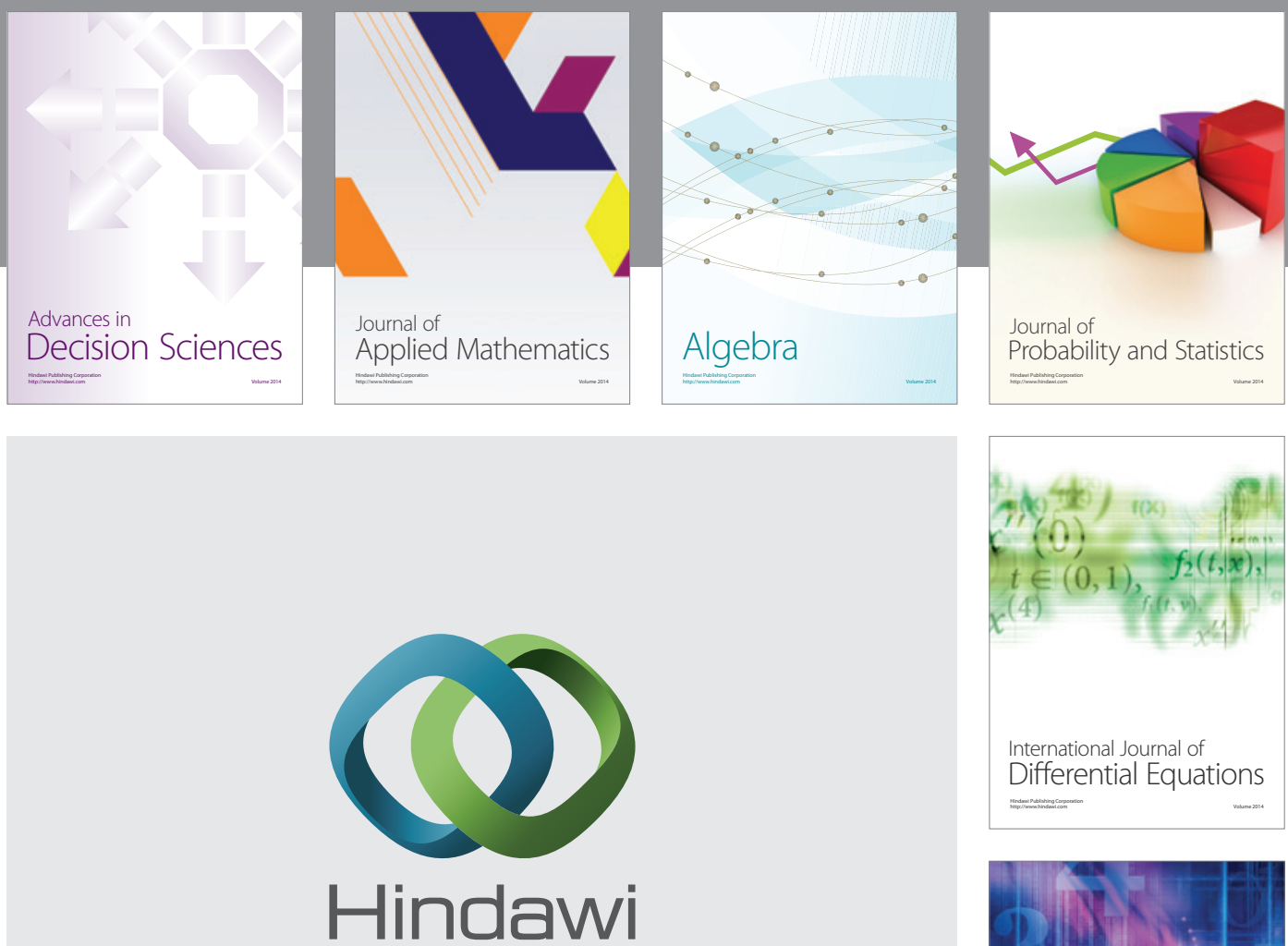

Submit your manuscripts at http://www.hindawi.com
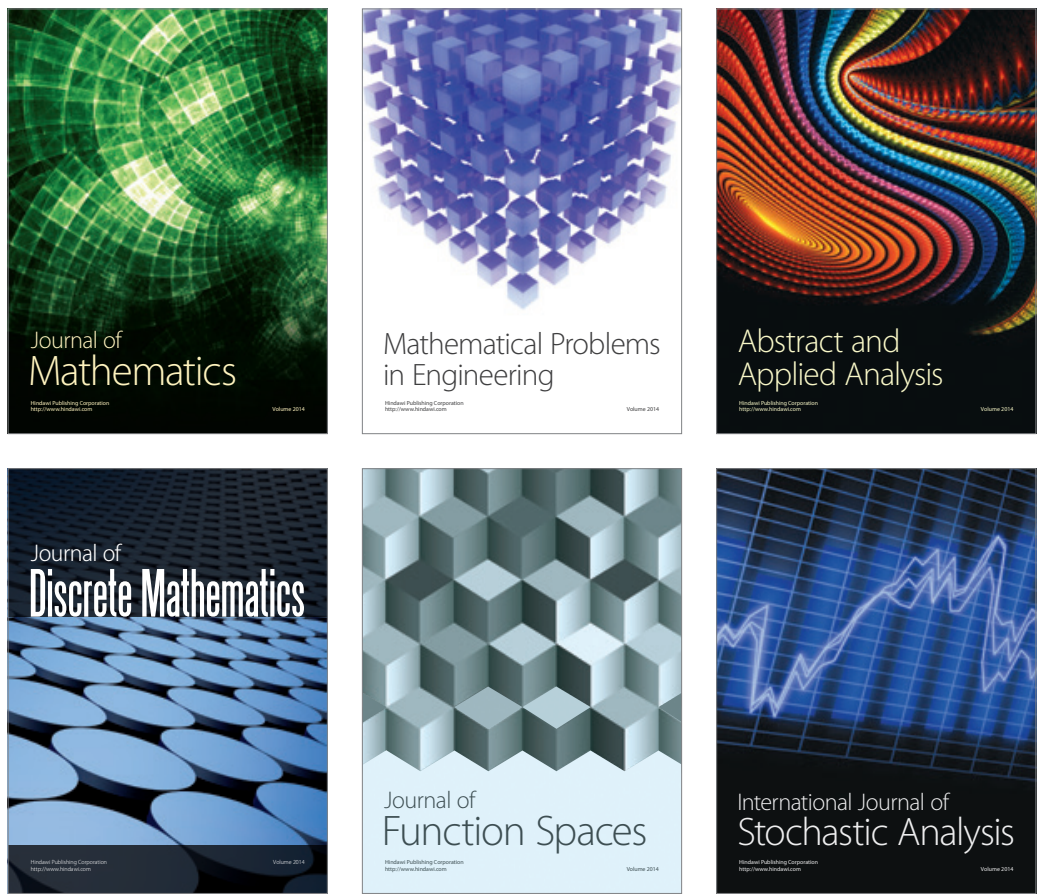

Journal of

Function Spaces

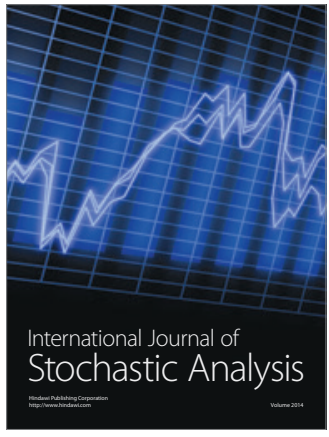

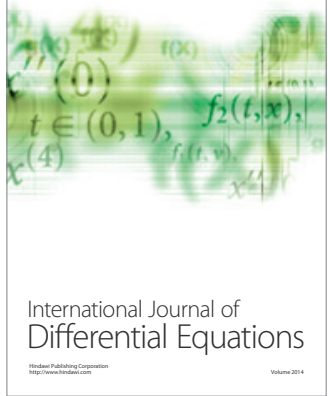
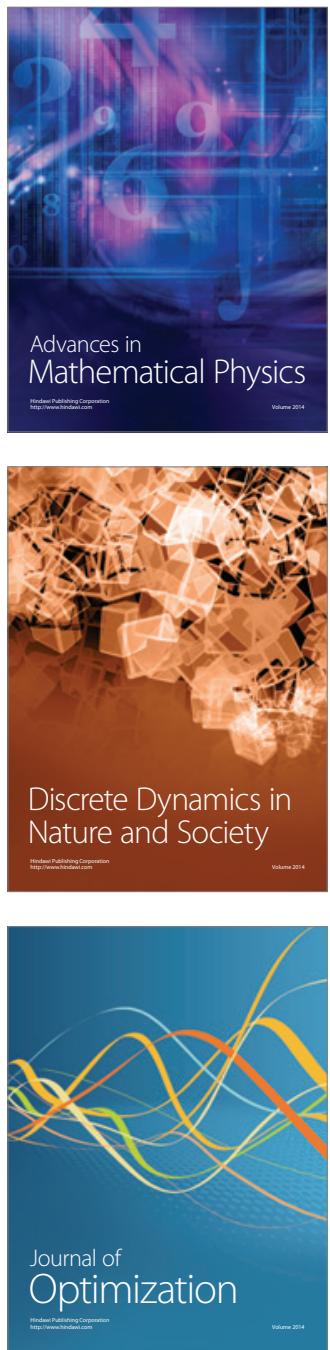